\title{
Analisis Stabilitas pada Perbaikan Tanah Lunak Metode Preloading dengan Menggunakan Metode Elemen Hingga
}

\author{
ERDINA TYAGITA UTAMI', INDRA NOER HAMDHAN², \\ KABUL SUWITAATMADJA ${ }^{3}$
}

1. Institut Teknologi Sumatera

2. Institut Teknologi Nasional Bandung

3. PT Soilens

Email: erdina.utami@si.itera.ac.id

\begin{abstract}
ABSTRAK
Tanah lunak merupakan tanah dengan stabilitas rendah yang dapat mengalami penurunan yang besar saat diberi beban. Preloading adalah salah satu cara memperbaiki tanah lunak tersebut. Penelitian ini bertujuan untuk mengetahui stabilitas tanah lunak akibat perbaikan tanah menggunakan preloading. Pemodelan dilakukan dengan cara menghitung kenaikan kuat geser tanah. Untuk mencari faktor keamanan dan bidang longsor dilakukan pemodelan dengan menggunakan Metode Elemen Hingga Plaxis 2D dengan pembebanan 2 tahap. Pembebanan pertama yang dilakukan adalah setinggi 5 meter dan pembebanan ke dua yaitu setinggi 1-2 meter. Jarak perbaikan tanah juga dimodelkan dalam penelitian ini sejauh 5 meter, 10 meter, dan 15 meter dari sisi lokasi timbunan batu bara. Batasan faktor keamanan (SF) minimum terhadap keruntuhan adalah 1,5. Perbaikan tanah dengan metode preloading menyebabkan tanah akan memampat dan dapat stabil dalam menerima beban.
\end{abstract}

Kata kunci: tanah lunak, stabilitas tanah, preloading, faktor keamanan, metode elemen hingga

\begin{abstract}
Soft soils are soils with low stability which can experience a large settlement under loading process. Preloading is one of the ways to improve the soft soil. This study aims to determine the stability of soft soils due to soil improvement using preloading. Modeling is done by calculating the increase in soil shear. To find the safety factor and the landslide field, modeling is done using Finite Element Method 2D Plaxis by two stages of loading. The first loading is 5 meters high and the second loading is 1-2 meters. Ground improvement distances are also modeled in this study as far as 5 meters, 10 meters and 15 meters from the side of the location of the coal emankment. The minimum safety factor (SF) limit to collapse is 1.5. Improvement of the soil using the preloading method causes the soil to compress and can be stable in receiving loads.
\end{abstract}

Keywords: soft soil, soil stability, preloading, safety factor, finite elemen method 


\section{PENDAHULUAN}

Tanah adalah material yang terbentuk dari himpunan material, bahan organik/anorganik, dan endapan lepas. Berdasarkan ukuran butirannya, tanah dibagi menjadi dua kelompok utama yaitu tanah berbutir kasar dan tanah berbutir halus. Tanah berbutir kasar digolongkan menjadi kerikil (gravel) dan pasir (sand). Sedangkan, tanah berbutir halus terdiri dari lanau (silt) dan lempung (clay). Tanah berbutir halus merupakan tanah yang memiliki daya lekat antar partikel yang biasanya disebut tanah kohesif (cohesive soils). Banyak tanah kohesif merupakan tanah lunak yang dapat mengembang atau menyusut akibat masuk atau keluarnya air. Tingkat kepekaan yang tinggi terhadap air, dapat menyebabkan stabilitas yang rendah, penurunan (settlement) yang cukup besar saat dibebani. Diperlukan proses stabilisasi pada tanah lunak sehingga memiliki stabilitas dan penurunan yang kecil. Preloading merupakan cara memperbaiki tanah lunak. Dengan melakukan perbaikan tanah dasar diharapkan tanah tersebut dapat menahan beban yang diberikan. Metode preloading dilakukan dengan cara membebani tanah lunak dengan timbunan material tertentu sehingga memberikan penurunan pada lapisan tanah lunak saat dibebani tanpa menyebabkan keruntuhan pada lapisan tanah lunak, sedangkan drainase vertikal digunakan untuk mempercepat waktu penurunan pada saat preloading dilakukan. Pada saat dilakukan proses preloading, tanah akan mengalami kenaikan kekuatan geser tanah dan terjadi proses kompresibilitas pada tanah tersebut. Untuk mengetahui pengaruh kenaikan kuat geser tanah akibat perbaikan tanah dengan preloading dilakukan mengkorelasikan data-data pengujian tanah dengan persamaan Stamatopoulus, A.C. dan Kotzias, P.C. (1985). Untuk mengetahui stabilitas tanah akibat adanya preloading dan beban rencana yang bekerja di atasnya (batu bara) maka dibuat pemodelan dan dilakukan analisis dengan menggunakan program komputer geoteknik berbasis elemen hingga yaitu Plaxis 2D.

\section{TINJAUAN PUSTAKA}

\subsection{Tanah Lunak}

Umumnya lapisan tanah yang disebut lapisan tanah lunak merupakan lanau (silt) dan lempung (clay). Berdasarkan USCS, butiran tanah pada lapisan ini memiliki ukuran butir < 0,0075 mm. Lapisan ini mempunyai nilai pengujian penetrasi standar N-SPT < 3, tekanan penetrasi bebas $\left(q_{u}\right)$ yang rendah yaitu $<0,5 \mathrm{~kg} / \mathrm{cm}^{2}$, kadar air tanah $\left(w_{n}\right)$ tinggi, dan tanah organik seperti gambut yang mempunyai kadar air alamiah yang sangat tinggi.

Salah satu pengujian di laboratorium yang digunakan untuk mengetahui jenis tanah yang diuji merupakan tanah lunak atau bukan yaitu pengujian Unconfined Compression Test (UCS) Berdasarkan percobaan-percobaan unconfined yang telah dilakukan, kekuatan tanah dapat diklasifikasikan sesuai Tabel 1.

Tanah lunak memiliki sifat mekanik yang kurang baik. Selain itu, tanah lunak memiliki kadar air yang tinggi, kompresibilitas tinggi, daya dukung rendah, stabilitas rendah, serta koefisien permeabilitas kecil yang akan mengakibatkan proses konsolidasi akan berlangsung dalam jangka waktu yang lama. 
Tabel 1. Perbedaan Pembebanan Jembatan

\begin{tabular}{|c|c|c|c|}
\hline $\begin{array}{c}\text { N SPT } \\
\text { [blows/ft] }\end{array}$ & Konsistensi & $\begin{array}{c}q_{u} \text { (Unconfined Compressive Strength) } \\
{\left[\text { ton } / \mathrm{ft}^{2}\right]}\end{array}$ & $\begin{array}{c}\gamma_{\text {sat }} \\
{\left[\mathrm{kN} / \mathbf{m}^{3}\right]}\end{array}$ \\
\hline$<2$ & Sangat Lunak & $<0,25$ & $16-19$ \\
\hline $2-4$ & Lunak & $0,25-0,5$ & $16-19$ \\
\hline $4-8$ & Medium & $0,5-1$ & $17-20$ \\
\hline $8-15$ & Kaku & $1-2$ & $19-22$ \\
\hline $15-30$ & Sangat kaku & $2-4$ & $19-22$ \\
\hline$>30$ & Keras & $>4$ & $19-22$ \\
\hline
\end{tabular}

(Sumber: Terzaghi, K. \& Peck, R.B., 1967)

\subsection{Konsep Stabilitas Tanah Timbunan}

Timbunan merupakan salah satu jenis lereng buatan manusia yang memiliki kemiringan tertentu dan dapat runtuh jika tidak dirancang dengan baik. Sifat material, metode konstruksi yang digunakan harus dirancang agar tidak terjadi keruntuhan pada lereng timbunan. Perancangan lereng timbunan didisain berdasarkan parameter kuat geser (shear strength).

Terkadang suatu timbunan dibuat di atas lapisan tanah asli berupa lempung. Keruntuhan dapat terjadi pada tanah di bawah timbunan tersebut. Oleh karena itu, perlu perhatian khusus untuk lapisan tanah lunak di bawah timbunan.

Tanah timbunan biasanya lebih kaku dan kuat dibandingkan dengan tanah dasar berupa tanah lunak. Hal itu memungkinkan timbunan akan mengalami patah saat lapisan tanah dasar berdeformasi, mengalami penurunan akibat beratnya sendiri, dan terjadi keruntuhan akibat tegangan dan regangan antara timbunan dan lapisan tanah dasar tersebut (Gambar 1). Oleh karena itu, perlu perbaikan tanah sehingga tanah dasar tersebut dapat memikul beban timbunan di atasnya.

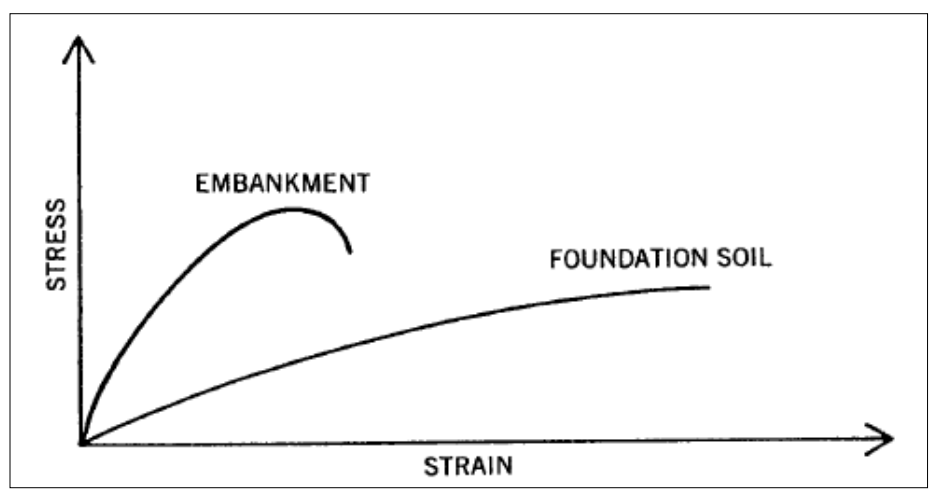

Gambar 1. Ilustrasi tegangan dan regangan timbunan dan tanah lempung (Sumber: Chirapuntu dan Duncan, 1977 dalam Abramson, L.W. et al, 2001)

\subsection{Kenaikan Kuat Geser Akibat Perbaikan Tanah dengan Preloading dan Drainase Vertikal}

Penggunaan pembebanan awal (preloading) merupakan teknik yang dapat memperbaiki tanah lunak. Teknik ini dapat meningkatkan kapasitas kekuatan tanah (bearing capacity) dan menurunkan kompresibilitas dari tanah lunak.

Preloading dilakukan dengan cara membebani tanah lunak dengan timbunan material tertentu sehingga memberikan penurunan pada lapisan tanah lunak saat dibebani tanpa menyebabkan keruntuhan pada lapisan tanah lunak yang dibebani. 
Berdasarkan buku Soil Improvement by Preloading (Stamatopoulus, A.C. dan Kotzias, P.C., 1985), terjadi perubahan pada parameter tanah akibat preloading. Perubahan yang terjadi yaitu perubahan nilai kadar air pada tanah.

Perubahan kadar air $\left(\Delta w_{n}\right)$ yang terjadi dapat dirumuskan oleh Persamaan 1.

$$
\Delta w_{n} \approx-\left(0,55+\frac{1}{G}\right) \frac{\Delta h}{h}=-\left(w_{N}+\frac{1}{G}\right) \frac{\delta}{h}
$$

dengan:

$$
\begin{array}{ll}
G & =\text { specific gravity }, \\
\Delta h & =\text { pengurangan ketebalan tanah, } \\
w_{N} & =\text { kadar air pada tanah, } \\
h & =\text { ketebalan tanah, } \\
\delta & =\text { penurunan konsolidasi yang terjadi. }
\end{array}
$$

Perubahan kuat geser tanah kondisi tidak teralirkan (Undrained Shear Strength, $S_{u}$ ) dapat dilihat pada Persamaan 2.

$$
\Delta S_{u} \approx \frac{1+w_{N} G}{0,434 C_{c}} * S_{u} * \frac{\delta}{h}
$$

dengan:

$C_{c} \quad=$ indeks pemampatan,

$S_{u} \quad=$ kuat geser tanah kondisi tidak teralirkan .

\subsection{Faktor Keamanan Timbunan}

Besarnya nilai faktor keamanan yang digunakan di dalam desain biasanya bervariasi antara $1,0-1,5$. Hal yang perlu dipertimbangkan dalam penentuan kriteria faktor kemananan adalah kondisi lingkungan, resiko yang dihadapi dan kondisi beban yang bekerja. Pada saat menganalisis harus diperhatikan kondisi beban gempa atau tanpa gempa. Gambaran mengenai besarnya nilai faktor keamanan yang diperlukan untuk suatu analisis stabilitas lereng tertentu dapat dilihat pada Tabel $\mathbf{2}$.

Tabel 2. Rekomendasi Nilai Minimum Faktor Keamanan Statik

\begin{tabular}{ccc}
\hline Biaya Konsekuensi Kelongsorang Lereng & \multicolumn{2}{c}{$\begin{array}{c}\text { Ketidakpastian } \\
\text { Pengukuran } \\
\text { Parameter Kuat Geser } \\
\text { Besar }\end{array}$} \\
\hline $\begin{array}{c}\text { Kecil } \\
\text { Biaya perbaikan dibandingkan terhadap konstruksi sama. } \\
\text { Tidak ada bahaya terhadap kehidupan manusia atau } \\
\text { properti lainnya. }\end{array}$ & 1,25 & 1,5 \\
\hline $\begin{array}{c}\text { Biaya perbaikan lebih besar terhadap biaya konstruksi, dan } \\
\text { berbahaya terhadap kehidupan manusia atau properti } \\
\text { lainnya. }\end{array}$ & 1,5 & 2 atau lebih besar \\
\hline
\end{tabular}

(Sumber: Duncan, J.M. \& Buchignani, A.L., 1975)

\section{ANALISIS DATA}

\subsection{Perancangan Model Geometri Lapisan Tanah}

Lapisan tanah lunak (soft clay) memiliki ketebalan $16 \mathrm{~m}$. Jarak perbaikan diukur dari kaki timbunan batu bara kearah luar dengan variasi jarak perbaikan 5, 10, dan $15 \mathrm{~m}$. Bagian tanah lunak yang diperbaiki merupakan daerah yang diasir pada Gambar 2. 


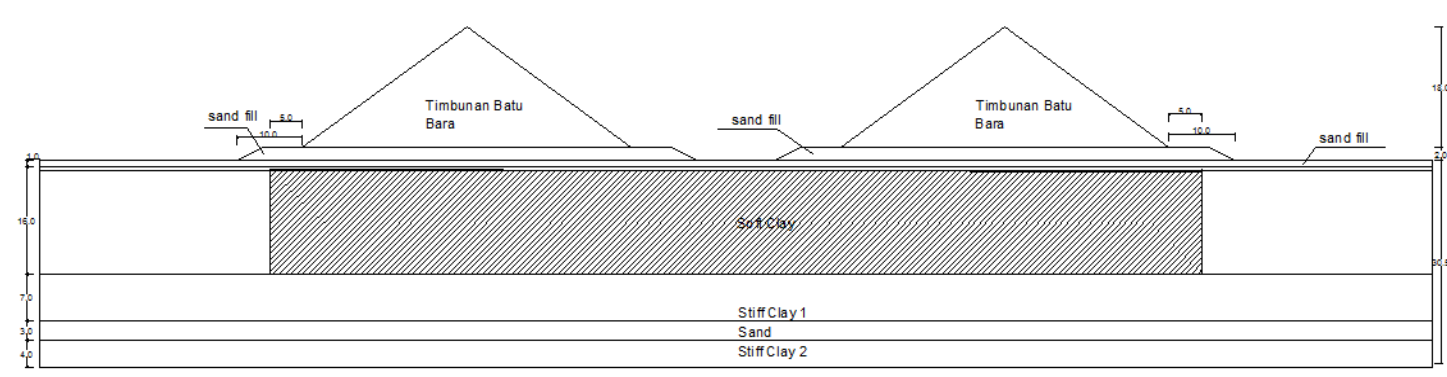

Gambar 2. Lapisan tanah, beban batu bara, dan jarak perbaikan $\mathbf{5} \mathbf{m}$

\subsection{Pengumpulan Data}

Hasil perhitungan kuat geser tanah lunak dapat dilihat pada Tabel 3. Data parameter lapisan-lapisan tanah yang digunakan dalam analisis ini dapat dilihat pada Tabel 4. Data lapisan tanah lunak (soft clay) diperoleh dari pengujian di lapangan dan di laboratorium yang telah dilakukan oleh PT. Soilens dan beberapa parameter tanah yaitu modulus elastisitas $(E)$, Angka Poisson $(\mu)$, diambil berdasarkan korelasi dari literatur yang ada.

Tabel 3. Hasil Perhitungan $S_{u}$ Tanah Lunak

\begin{tabular}{ccccc}
\hline Kedalaman & $\begin{array}{c}\boldsymbol{S} \text { Vane Shear } \\
{\left[\mathbf{k N} / \mathbf{m}^{2-}\right]}\end{array}$ & $\begin{array}{c}\boldsymbol{I}_{\boldsymbol{p}} \\
{[\%]}\end{array}$ & $\boldsymbol{\mu}$ & $\begin{array}{c}\boldsymbol{S}_{\boldsymbol{u}} \\
{\left[\mathbf{k N} / \mathbf{m}^{2-}-\right.}\end{array}$ \\
\hline $0,5-4,5$ & 37,082 & 53,1 & 0,77 & 28,6 \\
\hline $4,5-8,5$ & 29,626 & 55,8 & 0,76 & 22,5 \\
\hline $8,5-12,5$ & 31,097 & 53,3 & 0,77 & 23,9 \\
\hline $12,5-15,5$ & 41,496 & 82,2 & 0,65 & 27,0 \\
\hline & $\boldsymbol{S}_{\boldsymbol{u}}$ rata-rata & & & 25,5 \\
\hline
\end{tabular}

Tabel 4. Parameter Lapisan-lapisan Tanah

\begin{tabular}{ccccccc}
\hline Parameter & Satuan & Sand 1 & Soft Clay & Stiff Clay 1 & Sand & Stiff Clay 2 \\
\hline$\gamma_{\text {unsat }}$ & $\mathrm{kN} / \mathrm{m}^{3}$ & 16,20 & 15,15 & 16,2 & 16,7 & 16,5 \\
\hline$\gamma_{\text {sat }}$ & $\mathrm{kN} / \mathrm{m}^{3}$ & 19 & 15,80 & 17 & 19 & 18 \\
\hline$E$ & $\mathrm{kN} / \mathrm{m}^{2}$ & 15.000 & 2.500 & 25.000 & 65.000 & 25.000 \\
\hline$\mu$ & & 0,25 & 0,3 & 0,3 & 0,25 & 0,3 \\
\hline$S_{u}$ & $\mathrm{kN} / \mathrm{m}^{2}$ & - & 25,5 & 190 & - & 220 \\
\hline$c$ & $\mathrm{kN} / \mathrm{m}^{2}$ & 1 & - & - & 1 & - \\
\hline$\phi$ & $\circ$ & 35 & 0 & 0 & 40 & 0
\end{tabular}

\subsection{Data Beban yang Digunakan}

Beban timbunan (preloading) yang digunakan adalah tanah dengan berat isi $16,2 \mathrm{kN} / \mathrm{m}^{3}$. Dilakukan perhitungan daya dukung tanah ultimit berdasarkan konsep daya dukung Terzaghi sehingga diperoleh nilai $q_{u l t}$ sebagai berikut:

$$
\begin{aligned}
q_{u l t} & =S_{u} * N_{c} \\
& =25,5 * 5,14 \\
& =131,07 \mathrm{kN} / \mathrm{m}^{2}
\end{aligned}
$$

Sedangkan dengan nilai faktor keamanan minimum sebesar 1,5 ditentukan daya dukung ijin sebesar:

$$
\begin{aligned}
q_{\text {all }} & =\frac{q_{\text {ult }}}{S F} \\
& =\frac{131,07}{1,5} \\
& =87,38 \mathrm{kN} / \mathrm{m}^{2}
\end{aligned}
$$


Estimasi tinggi preloading yang dapat diterapka adalah maksimum 5,3 meter untuk satu tahap penimbunan. Penimbunan pertama dilakukan setinggi 5 meter.

$$
\begin{aligned}
\text { Estimasi tinggi preloading } & =\frac{q_{\text {all }}}{\gamma_{\text {tanah timbunan }}} \\
& =\frac{87,38}{16,2} \\
& =5,3 \mathrm{~m} \approx 5 \mathrm{~m}
\end{aligned}
$$

Setelah konstruksi selesai, tanah dasar yang sudah diperbaiki akan diberikan beban timbunan batu bara dengan berat isi $(\gamma)=9 \mathrm{kN} / \mathrm{m}^{3}$ dan memiliki tinggi timbunan $18 \mathrm{~m}$. Terdapat dua timbunan batu bara dengan tinggi dan berat jenis timbunan yang sama. Beban dimodelkan sebagai beban segitiga dengan beban maksimum $162 \mathrm{kN} / \mathrm{m}^{2}$.

\subsection{Faktor Keamanan Rencana}

Berdasarkan Tabel 2, faktor keamanan lereng rencana yaitu 1,5. Nilai ini digunakan karena mempertimbangkan faktor resiko yang menengah, tanpa adanya gempa, parameter kuat geser merupakan data yang maksimum, serta penentuan parameter kuat geser dilakukan secara teliti.

\subsection{Analisis Stabilitas Tanah Sebelum Dilakukan Perbaikan Tanah}

Tanah lunak dengan $S_{u}=25,5 \mathrm{kN} / \mathrm{m}^{2}$ dan $\phi=0^{\circ}$ dibebani timbunan batu bara berbentuk beban segitiga memiliki nilai SF sebesar 0,802 dan bidang longsor seperti Gambar 3. Tanah lunak tersebut harus diperbaiki sehingga memiliki stabilitas yang baik saat dibebani timbunan batu bara.

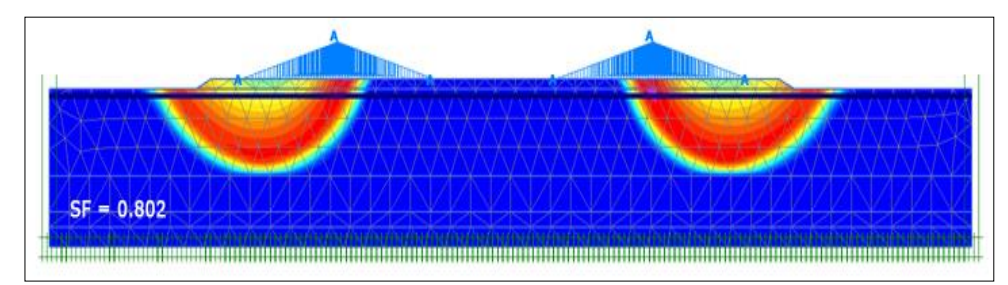

Gambar 3. Bidang longsor dan SF sebelum dilakukan perbaikan tanah

\subsection{Analisis Stabilitas Tanah Sebelum Dilakukan Perbaikan Tanah}

Berdasarkan buku Soil Improvement by Preloading (Stamatopaulus, A.C. dan Kotzias, P.C., 1985), terjadi perubahan pada parameter kuat geser tanah akibat preloading dapat dihitung dengan Persamaan 1 dan Persamaan 2.

Kadar air $\left(w_{n}\right)$ dan kuat geser $\left(S_{u}\right)$ akan berubah saat dilakukan perbaikan tanah dengan metode preloading menjadi nilai $w_{n_{1}}$ dan $S_{u_{1}}$. Tinggi preloading yang digunakan untuk tahap pertama yaitu $5 \mathrm{~m}$. Data perubahan tahap pertama dapat dilihat pada Tabel 5. Data parameter pada Tabel $\mathbf{6}$ dan Tabel $\mathbf{7}$ digunakan saat faktor keamanan (SF) tidak mencapai SF minimum yaitu 1,5. Pada Tabel 5, analisis menggunakan tinggi timbunan $2 \mathrm{~m}$ sedangkan pada Tabel 6, analisis menggunakan tinggi timbunan $1 \mathrm{~m}$. 
Tabel 5. Preloading Tahap 1, Tinggi Timbunan 5 m

\begin{tabular}{|c|c|c|c|c|c|c|}
\hline Kedalaman & $\begin{array}{c}\text { Tebal } \\
{[\mathrm{m}]}\end{array}$ & $\begin{array}{c}w_{n} \\
{[\%]}\end{array}$ & $\begin{array}{c}S_{u} \\
{\left[\mathrm{kN} / \mathrm{m}^{2}\right]}\end{array}$ & $\begin{array}{c}S_{u_{1}} \\
{\left[k N / m^{2}\right]}\end{array}$ & $\begin{array}{l}w_{n_{1}} \\
{[\%]}\end{array}$ & $\begin{array}{c}\text { Tebal Baru } \\
{[\mathrm{m}]}\end{array}$ \\
\hline $0,5-4,5$ & 4 & 48,5 & 28,553 & 82,589 & 32,593 & 3,621 \\
\hline $4,5-8,5$ & 4 & 73,1 & 22,516 & 36,702 & 67,804 & 3,812 \\
\hline $8,5-12,5$ & 4 & 72,3 & 23,945 & 33,376 & 68,989 & 3,882 \\
\hline $12,5-15,5$ & 3.5 & 104,8 & 26,973 & 38,158 & 101,314 & 3,409 \\
\hline \multicolumn{4}{|c|}{$S_{u}$ rata-rata } & 47,706 & Tebal & 14,723 \\
\hline
\end{tabular}

Tabel 6. Preloading Tahap 2, Tinggi Timbunan 2 m

\begin{tabular}{|c|c|c|c|c|c|c|}
\hline Kedalaman & $\begin{array}{c}\text { Tebal } \\
{[\mathrm{m}]}\end{array}$ & $\begin{array}{c}w_{n} \\
{[\%]}\end{array}$ & $\begin{array}{c}S_{u} \\
{\left[\mathrm{kN} / \mathrm{m}^{2}\right]}\end{array}$ & $\begin{array}{c}S_{u_{1}} \\
{\left[\mathrm{kN} / \mathrm{m}^{2}\right]}\end{array}$ & $\begin{array}{l}w_{n_{1}} \\
{[\%]}\end{array}$ & $\begin{array}{c}\text { Tebal Baru } \\
{[\mathrm{m}]}\end{array}$ \\
\hline $0,5-4,5$ & 3,621 & 32,593 & 82,589 & 100,810 & 30,738 & 3,574 \\
\hline $4,5-8,5$ & 3,812 & 67,804 & 36,702 & 44,852 & 66,002 & 3,779 \\
\hline $8,5-12,5$ & 3,882 & 68,989 & 33,376 & 40,007 & 67,371 & 3,852 \\
\hline $12,5-15,5$ & 3,409 & 101,314 & 38,158 & 45,038 & 99,774 & 3,391 \\
\hline \multicolumn{4}{|c|}{$S_{u}$ rata-rata } & 57,677 & Tebal & 14,597 \\
\hline
\end{tabular}

Tabel 7. Preloading Tahap ke 2, Tinggi Timbunan 1 m

\begin{tabular}{|c|c|c|c|c|c|c|}
\hline Kedalaman & $\begin{array}{c}\text { Tebal } \\
{[\mathrm{m}]}\end{array}$ & $\begin{array}{c}w_{n} \\
{[\%]}\end{array}$ & $\begin{array}{c}S_{u} \\
{\left[\mathrm{kN} / \mathrm{m}^{2}\right]}\end{array}$ & $\begin{array}{c}S_{u_{1}} \\
{\left[k N / m^{2}\right]}\end{array}$ & $\begin{array}{l}w_{n_{1}} \\
{[\%]}\end{array}$ & $\begin{array}{c}\text { Tebal Baru } \\
{[\mathrm{m}]}\end{array}$ \\
\hline $0,5-4,5$ & 3,621 & 32,593 & 82,589 & 92,341 & 31,600 & 3,596 \\
\hline $4,5-8,5$ & 3,812 & 67,804 & 36,702 & 41,018 & 66,850 & 3,795 \\
\hline $8,5-12,5$ & 3,882 & 68,989 & 33,376 & 36,861 & 68,139 & 3,866 \\
\hline $12,5-15,5$ & 3,409 & 101,314 & 38,158 & 41,756 & 100,509 & 3,400 \\
\hline \multicolumn{4}{|c|}{$S_{u}$ rata-rata } & 52,994 & Tebal & 14,656 \\
\hline
\end{tabular}

Kuat geser tanah akan mengalami peningkatan saat diberi beban preloading. Hal ini terjadi karena keluarnya air pori pada tanah lunak yang dapat menyebabkan tanah tersebut mengalami kompresibilitas. Ketebalan awal tanah lunak yaitu 16 meter mengalami pemampatan menjadi 14,723 meter saat diberi beban timbunan 5 meter. Jika ditambah timbunan 1 meter, terjadi perubahan ketebalan tanah menjadi 14,656 meter. Saat tanah tersebut diberi beban tambahan 2 meter, perubahan tebal tanah lunak menjadi 14,656 meter. Penurunan yang diakibatkan beban preloading pada tanah lunak yang terkonsolidasi tersebut adalah 1,344 meter setelah ditambah beban 7 meter.

\subsection{Analisis Stabilitas Akibat Preloading}

Setelah dilakukan perhitungan perubahan kadar air, kuat geser, dan tebal tanah lunak, dilakukan analisis stabilitas tanah dalam menahan beban batu bara. Faktor keamanan (SF) sebesar 1,5 sebagai batas tanah tersebut stabil dalam menerima beban yang bekerja. Gambar 4a merupakan hasil analisis preloading dengan jarak perbaikan $5 \mathrm{~m}$. Faktor keamanan yang diperoleh yaitu 1,386 lebih kecil dari faktor keamanan rencana. Preloading dilakukan 2 tahap. Tahap ke 2 digunakan tinggi preloading yaitu $2 \mathrm{~m}$. Perubahan parameter dapat dilihat pada Tabel 6, sehingga SF yang diperoleh yaitu 1,550 (Gambar 4b). 


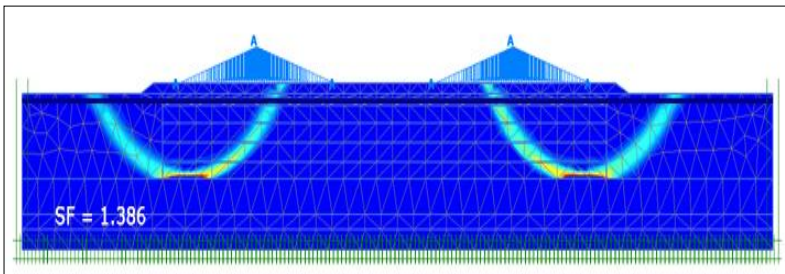

(a)

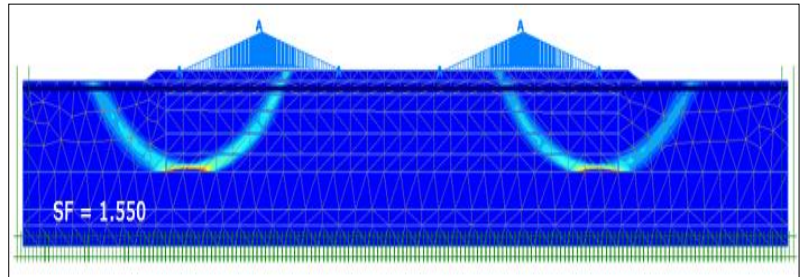

(b)

Gambar 4. Bidang longsor dan SF untuk jarak perbaikan 5 m

(a) preloading tahap 1 dan (b) preloading tahap 2

Gambar 5a merupakan hasil analisis preloading dengan jarak perbaikan $10 \mathrm{~m}$. SF yang diperoleh yaitu 1,419. Oleh karena itu, preloading dilakukan 2 tahap. Tahap ke 2 digunakan tinggi preloading yaitu $1 \mathrm{~m}$. Perubahan parameter dapat dilihat pada Tabel 7 sehingga SF yang diperoleh yaitu 1,515 (Gambar $\mathbf{5 b}$ ).

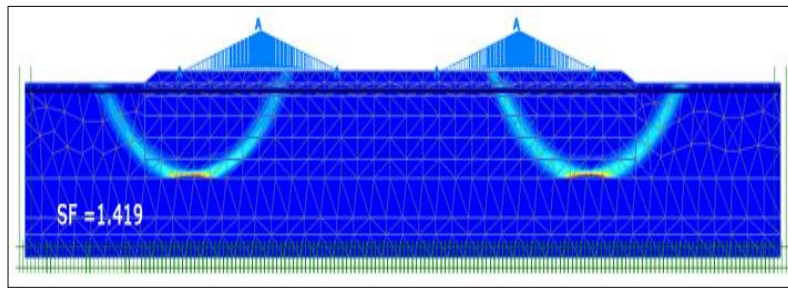

(a)

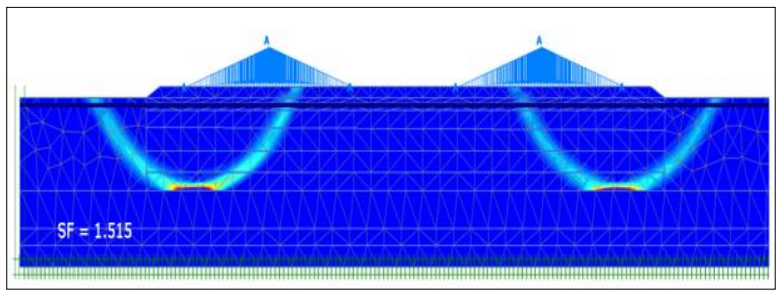

(b)

Gambar 5. Bidang longsor dan SF untuk jarak perbaikan $10 \mathrm{~m}$ (a) preloading tahap 1 dan (b) preloading tahap 2

Gambar 6a merupakan hasil analisis preloading dengan jarak perbaikan $15 \mathrm{~m}$. SF yang diperoleh yaitu 1,430. Oleh karena itu, preloading dilakukan 2 tahap. Tahap ke 2 digunakan tinggi preloading yaitu $1 \mathrm{~m}$. Perubahan parameter dapat dilihat pada Tabel 7 sehingga diperoleh SF = 1,528 (Gambar 6b).

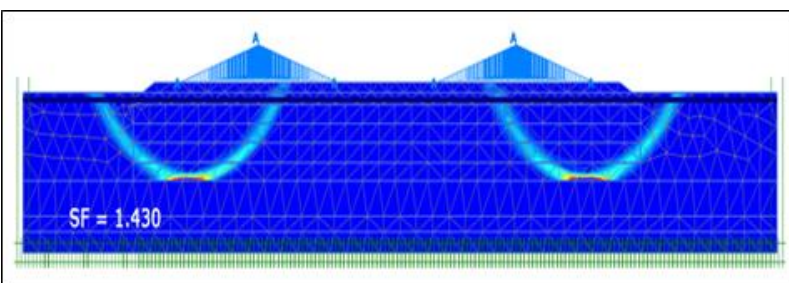

(a)

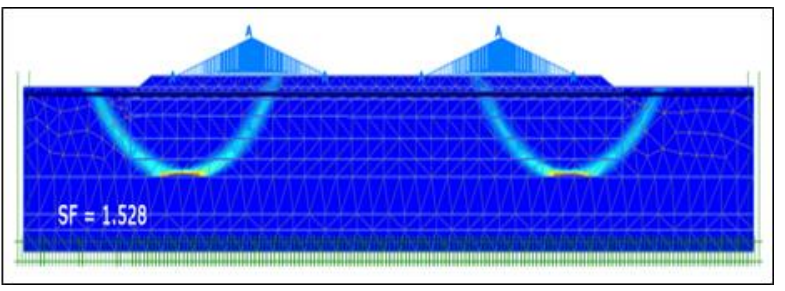

(b)

Gambar 6. Bidang longsor dan SF untuk jarak perbaikan 15 m (a) preloading tahap 1 dan (b) preloading tahap 2

Rekapitulasi hasil analisis preloading dapat dilihat pada Tabel 8. Semakin jauh jarak perbaikan tanah dari kaki tinggi timbunan memberikan nilai SF lebih besar. Jarak perbaikan 15 meter memberikan nilai faktor keamanan lebih besar yaitu 1,528. Dengan faktor keamanan yaitu 1,5; perbaikan tanah memerlukan 2 kali tahapan penimbunan. Kisaran tinggi timbunan yang dibutuhkan untuk perbaikan tanah yaitu 6-7 meter. 
Tabel 8. Rekapitulasi Faktor Keamanan

\begin{tabular}{cccc}
\hline $\begin{array}{c}\text { Jarak } \\
\text { Perbaikan } \\
{[\mathbf{m}]}\end{array}$ & $\begin{array}{c}\text { Tahapan } \\
\text { Penimbunan }\end{array}$ & $\begin{array}{c}\text { Tinggi Timbunan } \\
\text { yang Dibutuhkan } \\
{[\mathbf{m}]}\end{array}$ & SF \\
\hline \multirow{2}{*}{5} & 1 & 5 & 1,386 \\
\cline { 2 - 4 } & 2 & 2 & 1,550 \\
\hline \multirow{2}{*}{10} & 1 & 5 & 1,419 \\
\cline { 2 - 4 } 15 & 2 & 1 & 1,515 \\
\cline { 2 - 4 } & 1 & 5 & 1,430 \\
\hline
\end{tabular}

\section{KESIMPULAN}

Dari hasil analisis dan pembahasan yang telah dilakukan maka dapat ditarik kesimpulan sebagai berikut:

1. Jarak perbaikan dan tinggi timbunan mempengaruhi nilai faktor keamanan. Semakin jauh jarak perbaikan maka semakin besar nilai faktor keamanan. Semakin pendek jarak perbaikan, maka semakin kecil nilai faktor keamanan.

2. Estimasi awal tinggi timbunan yaitu $5 \mathrm{~m}$ untuk perbaikan tanah cara preloading tidak menghasilkan nilai SF $=1,5$. Oleh karena itu dilakukan preloading 2 tahap.

3. Kisaran tinggi timbunan yang dibutuhkan yaitu 6-7 meter bergantung terhadap jarak perbaikan. Semakin dekat jarak perbaikan, tinggi timbunan semakin tinggi. Semakin jauh jarak perbaikan, tinggi timbunan yang diperlukan semakin rendah.

4. Dengan adanya beban preloading, tanah lunak akan memampat dan kekuatan tanah akan naik sehingga tanah tersebut dapat menerima beban.

5. Nilai faktor keamanan terbesar; terjadi pada jarak perbaikan sejauh 15 meter dari kaki timbunan beban rencana batu bara; dengan nilai faktor keamanan sebesar 1,528.

\section{DAFTAR RUJUKAN}

Abramson, L.W. et al. (2001). Slope Stability and Stabilization Methods $2^{\text {nd }}$ Edition. New York: John Wiley \& Sons Inc.

Duncan, J.M. \& Buchignani, A.L. (1975). An Engineering Manual for Slope Stability Studies. Berkeley: Dept of Civil Engineering - University of California.

Stamatopoulos, A.C. \& Kotzias, P.C. (1985). Soil Improvement by Preloading. New York: John Wiley \& Sons Inc.

Terzaghi, K. \& Peck, R.B. (1967). Soil Mechanics in Engineering Practice $2^{\text {nd }}$ Edition. New York: John Wiley \& Sons Inc. 